УДК 130.2

$10.17213 / 2075-2067-2021-3-84-89$

\title{
СОВРЕМЕННАЯ ИНФОРМАЦИОННАЯ КОММУНИКАЦИЯ КАК ФАКТОР ВЫСТРАИВАНИЯ МЕЖЭТНИЧЕСКИХ ОТНОШЕНИЙ
}

\author{
(C) 2021 г. Е. А. Слизский
}

\section{Адыгейский государственный университет (филиал), г. Белореченск, Россия}

Россия - многонациональное государство, и это определяет серьезньле социальные риски, связанные с характером межэтнического взаимодействия. Различия в культуре, нормах поведения, ценностных ориентациях и способе мировоззрения в целом могут стать одним из серьезных оснований развития конфликтности. При этом одним из наиболее опасных социальных состояний является развитие межгруппового конфликта. В рамках статьи доказывается, что межгрупповая конфронтация сильно зависит от среды коммуникации членов общества. На этом основании делается вывод о том, что изменение механизмов информачионного взаимодействия способствует трансформации предпосылок развития межггрупповой конфликтности. В рамках анализа изменений в коммуникативной сфере, связанных с формированием механизмов массовой коммуникаџии, ставится вопрос о социальных рисках в сфрере межэтнического взаимодействия, связанных с современным состоянием коммуникативной сферь.

Ключевые слова: общество; этнос; этническая группа; межгрупповая конфронтацчия; информация; информационные технологии; социальное мировоззрение.

\section{MODERN INFORMATION COMMUNICATION AS A FACTOR IN BUILDING INTER-ETHNIC RELATIONS}

\section{(C) 2021 E. A. Slizsky}

\section{Adyghe State University (branch), Belorechensk, Russia}

Russia is a multinational state, and this defines serious social risks associated with the nature of inter-ethnic interaction. Differences in culture, norms of behavior, value orientations and the way of worldview in general can become one of the serious grounds for the development of conflict. At the same time, one of the most dangerous social conditions is the development of intergroup conflict. Within the framework of the article, it is proved that intergroup confrontation strongly depends on the communication environment of members of society. On this basis, it is concluded that changing the mechanisms of information interaction contributes to the transformation of the prerequisites for the development of intergroup conflict. As part of the analysis of changes in the communicative sphere related to the formation of mass communication mechanisms, the question is raised about social risks in the field of inter-ethnic interaction related to the modern state of the communicative sphere.

Key words: society; ethnic group; intergroup confrontation; information; information technologies; social outlook. 
Существование общества сопряжено с непрерывным действием консолидирующих и конфронтационных процессов в общественной среде, частично уравновешивающих друг друга. В условиях преобладания механизмов консолидации и интеграции членов общества происходит стабилизация общественной структуры и ее активное развитие. В свою очередь, преобладание конфронтационных механизмов ведет к нарушению системы социального взаимодействия, результатом которого может стать развитие серьезного социального конфликта, утрата функциональности институциональных структур, в которые включены конфликтующие стороны, общая дестабилизация социальной системы. Чем более сложным и в содержательном плане многообразным является общество, тем актуальнее вопрос о необходимости действия консолидирующих социальных факторов. Как отмечал известный французский социолог Э. Дюркгейм, по мере развития общества, его усложнения и соответственно стратификации, помимо социально-интегрирующих механизмов, основанных на сходстве членов общества по определенным признакам, все большую значимость приобретают интегрирующие факторы, направленные на преодоление естественной конфронтации различающихся между собой людей. В качестве такового основания консолидации исследователь рассматривал органическую солидарность, основанную на совместной включенности носителей разных социальных признаков в определенную систему отношений, в которой каждый участник взаимодействия значим в силу выполнения социальных функций, имеющих значение для среды включенности [1].

В данном случае ключевым моментом является характер взаимной идентификации членов общества: он может быть реализован с упором на область социальных различий либо с акцентуацией внимания на обобщающем факторе совместной социальной включенности. Подчеркнем: в рамках социального взаимодействия члены общества могут отмечать различные аспекты собственной социальной определенности и социальной определенности взаимодействующих с ними субъектов. Однако от того, какие именно аспекты социальной определенности другого будут оцениваться как приоритетные при его идентификации, во многом зависит, какое конечное отношение будет сформировано в его адрес и соответственно какой социальный механизм вступит в действие - интеграционный или конфронтационный.

В вопросе действия интеграционных и конфронтационных процессов в обществе одним из ключевых факторов является то, насколько разнородным является общество, и в частности - насколько серьезные различия имеют место между членами общества по определенным критериям, таким как материальный статус, социокультурная определенность членов общества, наличие прав и социальных возможностей членов общества и т.д. Чем меньшая проявленность различий имеет место в социальной среде, тем менее вероятным является возникновение конфронтационных процессов в обществе. Типичным примером является имущественное неравенство, выступающее одним из оснований социальной напряженности тем интенсивнее, чем выше уровень неравенства. Вместе с тем одним из наиболее серьезных оснований формирования разобщенности в обществе является различие по критерию культурной определенности. Разные ценностные ориентации, разные мировоззрения, разное понимание приемлемого и неприемлемого поведения - это основание, которое определяет сложности выстраивания взаимодействия между людьми, и в частности вероятность возникновения конфликтов, основанных на расхождении во взглядах. В этом плане общества, в которых совместно проживают представители разных этнических групп, сталкиваются с серьезными рисками возникновения противоречий и конфликтов, основанных на этнокультурных различиях представителей разных народностей.

Для России, являющейся многонациональным государством, проблема выстраивания конструктивного взаимодействия между представителями различных этнических групп, в частности недопущения развития конфронтационных тенденций в межэтнической среде, обладает высоким уровнем приоритетности. Это является тем основанием, которое определяет актуальность и практическую значимость исследований, посвященных социальным факторам выстраивания от- 
ношений в межэтнической среде. Настоящая статья ориентирована на раскрытие социокультурного аспекта выстраивания межэтнических отношений, связанного с репрезентацией образов представителей различных этнических групп в информационно-коммуникативном пространстве общества.

Прежде всего, следует отметить, что существует серьезное различие между частными процессами, протекающими в межэтнической среде, и межгрупповым взаимодействием представителей разных этносов. В первом случае этническая принадлежность является сопутствующим фактором в частной практике социального взаимодействия, и причины как конструктивных, так и конфликтных отношений лежат вне сферы этнической определенности действующих субъектов. До тех пор, пока частный опыт сохраняет статус частного опыта, речь идет о естественном социальном процессе, в котором решающее значение имеет совокупность индивидуальных социальных качеств действующих субъектов. Однако, как только групповая определенность становится фактором выбора модели отношения или модели социальной активности, осуществляемой применительно к конкретному человеку по факту его групповой принадлежности, индивидуальный аспект утрачивает свою значимость. Групповое взаимодействие не может существовать вне мировоззренческих установок, программирующих определенный способ выстраивания отношений, иными словами, в условиях, когда определенная форма взаимодействия выходит на межгрупповой уровень, речь идет о социальной модели, действующей на уровне мировоззрения членов общества. Перейдя к этому тезису, мы фактически обозначаем момент необходимой взаимосвязи между характером межэтнических отношений и характером социального мировоззрения представителей разных этнических групп. Причем в данном случае имеют место два решающих момента:

- характер социального восприятия представителей инаковой группы;

- область приоритетов в формировании идентификационных стратегий представителей различных этносоциальных групп.

Рассмотрим данные аспекты межэтнического взаимодействия подробнее. Что ка- сается характера социального восприятия представителей другого этноса, в данном случае ключевое значение имеет то, какие представления о конкретном этносе присутствуют на уровне индивидуального и группового социального мировоззрения. Нередко представления о конкретном народе ограничиваются набором этнических стереотипов, мало соответствующих действительности [2]. Этнические стереотипы необязательно носят негативный характер - может иметь место представление об определенной выдающейся черте представителей определенного этноса. Однако наличие этнических стереотипов не способствует выстраиванию конструктивного социального взаимодействия, поскольку стереотипное восприятие, по сути, ограничивает процесс социального познания расхожими представлениями, мешая процессу узнавания друг друга между представителями разных этносов. В данном случае формирование конструктивного социального восприятия представителей иноэтнических групп реализуется преимущественно вопреки существующим общегрупповым представлениям.

Рассматривая вопрос об области приоритетов в формировании идентификационных стратегий в межэтнической среде, следует отметить, что речь идет о том значении, которое участники общественных отношений придают собственной этнической маркированности и этнической определенности представителей других народностей. Рассмотренный выше вариант индивидуального выстраивания отношений (который по факту является одним из наиболее благоприятных) реализуется в том случае, если этническая определенность субъектов взаимодействия не является ключевым фактором выстраивания общественных отношений. Это может иметь место либо в том случае, когда отсутствует активная стереотипизация представителей определенных этнических групп, либо когда общегрупповые представления не являются чем-то актуальным, воспринимаемым всерьез. Причем следует отметить, что существует два основных аспекта отражения иноэтнической группы в социальном мировоззрении:

- представления об определенных социальных качествах, присущих представителям определенной этносоциальной группы; 
- представления о характере их активности в отношении этнической группы, к которой относится субъект социального восприятия.

В данном случае очень важно понимать, что идентификация иноэтнической группы как аспект социального мировоззрения может иметь либо единичный характер (в случаe, когда носителем определенных форм социального отношения к конкретному этносу является отдельный человек), либо групповой характер. Последний вариант может иметь место только в том случае, если конкретные представления и конкретная форма отношения становятся объектом репрезентации в коммуникативной среде - именно общие социальные условия и возможность коммуникации определяют процесс формирования коллективного мировоззрения. Таким образом, мы приходим к следующей логической цепочке: характер идентификации иноэтнической группы и межэтнические отношения в целом зависят от мировоззренческих установок вовлеченных в эти отношения людей. В свою очередь, наиболее опасные для общества межгрупповые конфронтационные процессы в межэтнической среде становятся возможными в том случае, когда негативные мировоззренческие установки приобретают групповой характер. Это становится возможным только в том случае, когда определенные негативные представления, формы отношения, негативный социальный опыт становятся транслируемыми в коммуникативной среде. Причем у всякого негативного этнического стереотипа имеет место двойное воздействие на область социальной практики: с одной стороны, речь идет о влиянии на социальное мировоззрение тех, кто воспринимает стереотипное представление и встраивает его в свою социальную картину мира, с другой - этнические стереотипы нередко остро воспринимаются представителями этноса, отражаемого на уровне данных стереотипов, что в значительной степени затрудняет для них процесс выстраивания внешнего (по отношению к их этнической группе) взаимодействия.

На данном этапе целесообразно рассмотреть место коммуникативных процессов в общей системе источников социального мировоззрения и соответственно определить их конечное влияние на процессы выстраивания общественных отношений. Здесь следует обратить внимание на то, что формирование мировоззрения реализуется двумя основными путями:

— через получение личного опыта;

- через получение знаний об окружающей действительности из внешних источников.

В современном мире доминирующее значение в формировании мировоззрения играет заимствование знаний, накопленных другими людьми, или, иными словами, опосредованное познание [3]. Это связано с тем, что большинство знаний об окружающей действительности является продуктом коллективной познавательной деятельности, при этом познавательные возможности одного человека имеют ограниченный характер, ввиду которого для него является нереализуемой задача по подтверждению всей совокупности наличествующих знаний на личном опыте. По этой причине знания, которые заимствуются человеком извне, зачастую не ставятся под вопрос и воспринимаются наравне с личным опытом (в особенности, если имеет место авторитетный источник). А. Шютц отмечает, что процесс познания социального мира не является индивидуальным - он обусловлен характеристиками мировоззрения ближайшего окружения человека [4]. При этом следует отметить, что по мере расширения области коммуникации, в которую вовлечен человек, количество источников опосредованного познания может существенно возрасти. И здесь необходимо подчеркнуть, что в современных условиях требуют пересмотра представления о среде коммуникации, в рамках которой формируются основы мировоззрения членов общества, поскольку помимо непосредственного социального окружения (семья, одноклассники, соседи и т.д.) в настоящее время одним из важнейших источников формирования социального мировоззрения становятся информационные источники, доступные в рамках обращения к ключевым медиа - телевидению, печатной прессе, области Интернет-коммуникации.

Несмотря на то, что воздействие ключевых медиа в ряде случаев носит односторонний характер, они вписываются в критерии определения авторитетного источника 
информации, к которому члены общества испытывают доверие, причем, что немаловажно, формирование информационной продукции нередко носит адресный характер, будучи ориентированным на определенную целевую аудиторию. Также следует отметить, что в настоящее время процессы цифровой коммуникации прочно входят в жизнь членов общества, составляя весомую конкуренцию «живому» общению, при этом особенности сетевого взаимодействия таковы, что даже диалог двух людей, будучи размещенным в рамках публичных информационных ресурсов, может стать достоянием широкой аудитории и, соответственно, оказывать мощное воздействие на мировоззрение членов общества.

Важнейшим моментом в данном случае становится то, что современные информационные технологии способствуют, с одной стороны, активному тиражированию информации и ее массовому воздействию на членов общества, с другой - способствуют неравномерному распределению опосредованного социального опыта в коммуникативной среде. Поясняя последнее, следует отметить, что ранее информация о каком-либо значимом событии, выбивавшемся из общей социальной практики, становилась достоянием того человека, с которым оно произошло, и его социального окружения. В настоящее время, благодаря развитию информационных технологий, социальный опыт одного человека может стать опытом миллионов. И если этот опыт носит негативный характер, общественный резонанс может иметь очень разрушительные последствия. При этом немаловажно, что активному распространению в информационной среде подлежит в первую очередь то, что выбивается из нормы.

Это способствует серьезному искажению восприятия социальной действительности, поскольку создается перекос в сторону репрезентации неожиданно позитивных и крайне негативных социальных явлений, без серьезного внимания к нормальному протеканию общественного процесса. В этой системе координат, что характерно, оба варианта трансляции информационной продукции, посвященной нетитульным этносам, несут в себе серьезные социальные риски. Это связано с тем, что описание социальных конфликтов, подтверждающих негативные этнические стереотипы, равно как и описание случаев, выступающих «исключением из правила» стереотипного восприятия, в конечном счете способствуют закреплению стереотипных моделей восприятия представителей конкретных этносов. Серьезные риски в данном случае связаны с тем, что в информационной среде производится активная актуализация этнических признаков, в то время как преодолению межэтнической конфронтации могла бы способствовать, в первую очередь, деактуализация механизмов идентификации по этническому критерию и актуализация иных механизмов социальной идентификации.

\section{Литература}

1. Дюркгейм Э. О разделении общественного труда. Метод социологии: пер. с фр. / Э. Дюркгейм, А.Б. Гофман, В.В. Сапов. М.: Наука, 1991. - 572 с.

2. Завалишин А. Ю., Костюрина Н. Ю. Этнические стереотипы: экспликация и анализ// ЖССА. — 2017. — №2. — C. 177-196.

3. Маклюэн М. Понимание медиа: внешние расширения человека. - М., 2003.

4. Шюти А. Смысловая структура повседневного мира: очерки по феноменологической социологии / Сост. А. Я. Алхасов; пер. с англ. А.Я. Алхасова, Н.Я. Мазлумяновой; научн. ред. перевода Г.С. Батыгин. - М.: Институт Фонда «Общественное мнение», 2003. - $336 \mathrm{c}$.

\section{References}

1. Djurkgejm Je. O razdelenii obshhestvennogo truda. Metod sociologii [On the division of social labor. Method of sociology]: per. s fr. / Je. Djurkgejm, A. B. Gofman, V. V. Sapov. - Moscow: Nauka, 1991. - 572 p.

2. Zavalishin A. Ju., Kostjurina N. Ju. Jetnicheskie stereotipy: jeksplikacija i analiz [Ethnic stereotypes: explication and analysis] // ZhSSA. 2017. — №2. — Pp. 177-196.

3. Makljujen M. Ponimanie media: vneshnie rasshirenija cheloveka [Understanding media: external extensions of a person]. - Moscow, 2003. 
4. Shjutc A. Smyslovaja struktura povsednevnogo mira: ocherki po fenomenologicheskoj sociologii [The semantic structure of the everyday world: essays on phenomenological sociol- ogy] / Sost. A. Ja. Alhasov; per. s angl. A. Ja. Alhasova, N. Ja. Mazlumjanovoj; in G.S. Batygin (eds.). - Moscow: Institut Fonda «Obshhestvennoe mnenie», 2003. - $336 \mathrm{p}$.

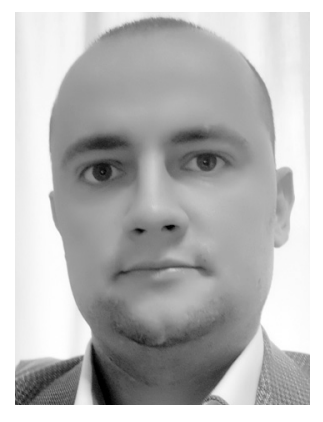

Слизский Евгений Анатольевич - старший преподаватель кафедры Белореченского филиала Адыгейского государственного университета.

Slizsky Evgeny Anatolievich - Senior Lecturer of the Department, Belorechensk branch of Adyghe State University.

350007, г. Краснодар, ул. Тахтамукайская, 9

9 Takhtamukaiskaya st., 350007, Krasnodar, Russia

E-mail: slizskiy@bk.ru 